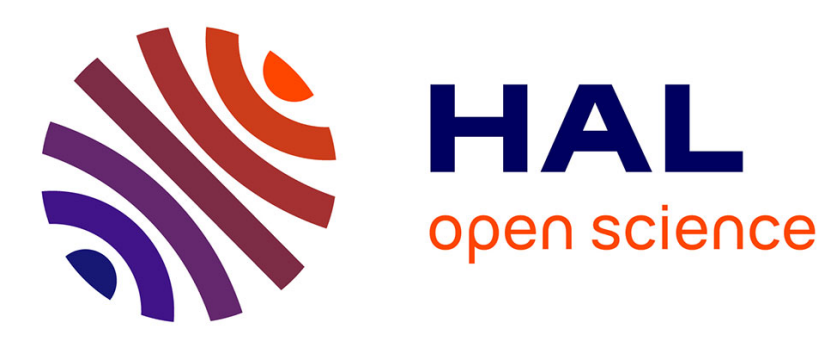

\title{
Design-for-Cost - An Approach for Distributed Manufacturing Cost Estimation
}

\author{
Minchul Lee, Boonserm (serm) Kulvatunyou
}

\section{To cite this version:}

Minchul Lee, Boonserm (serm) Kulvatunyou. Design-for-Cost - An Approach for Distributed Manufacturing Cost Estimation. IFIP International Conference on Advances in Production Management Systems (APMS), Sep 2019, Austin, TX, United States. pp.457-465, 10.1007/978-3-030-29996-5_53 . hal-02460472

\section{HAL Id: hal-02460472 \\ https://hal.inria.fr/hal-02460472}

Submitted on 30 Jan 2020

HAL is a multi-disciplinary open access archive for the deposit and dissemination of scientific research documents, whether they are published or not. The documents may come from teaching and research institutions in France or abroad, or from public or private research centers.
L'archive ouverte pluridisciplinaire HAL, est destinée au dépôt et à la diffusion de documents scientifiques de niveau recherche, publiés ou non, émanant des établissements d'enseignement et de recherche français ou étrangers, des laboratoires publics ou privés. 


\title{
Design-for-Cost - An Approach for Distributed Manufacturing Cost Estimation
}

\author{
Minchul Lee ${ }^{1}$ and Boonserm (Serm) Kulvatunyou ${ }^{1}$ \\ ${ }^{1}$ Systems Integration Division, National Institute of Standards and Technologies \\ \{ minchul.lee, serm \} @nist.gov
}

\begin{abstract}
Research has shown that design changes cost more in later stages of product development. Therefore, companies adopt Design-for-X methods to optimize product designs for many aspects in the early design stage. Despite such efforts, products often encounter several design changes during the commission of the production, a principal reason being failure to meet target costs. Accurately estimating cost in the early design stage is difficult due to insufficient information. In particular, as production becomes more distributed cost estimation is also more difficult because information is more distributed. This paper introduces a cost estimation method to address this problem. It describes a distributed manufacturing situation and a cost breakdown framework. A use case is provided to illustrate how the framework allows for supply-chain cost negotiation and design adjustments in the early design stage.
\end{abstract}

Keywords: Cost Estimation, New Product Introduction, Cost Breakdown Approach, Design-for-Cost, Supply Chain Management.

\section{Introduction}

Research has shown that design changes cost more in later stages of product development [1]. Therefore, companies adopt Design-for-X methods to optimize the product design from many aspects such as quality, time to delivery and cost in the early design stage. Companies have strong interest in the ability to accurately estimate manufacturing cost earlier in the design stage, because executives typically focus on maximizing profit.

In the New Product Introduction (NPI) process, companies typically set target market, volume, price, and manufacturing cost along with the design and functions of a product at the first stage [2]. They are very interested in maintaining the profit margin; therefore, target manufacturing costs are validated at every NPI stage. Despite this general practice, unexpected costs usually shows up at the commission of production because the current cost estimation approach is insufficient for today's distributed manufacturing environment. 
Traditionally, manufacturers ${ }^{1}$ have most of the information necessary for cost estimation. It is not the case for distributed manufacturing. Manufacturers need to interact with suppliers, estimate component costs, and consider delivery and packaging costs from the early design stage. Cost estimation approaches for distributed manufacturing need to enable manufacturers to negotiate with suppliers and come up with supply chain strategies that reduce cost. For example, in addition to the typical design adjustments to reduce material and manufacturing process costs, manufacturers may find suppliers who can use the same material and purchase the material on behalf of all the suppliers to receive a larger bulk-buying discount. Without proper cost break down in the estimation, manufacturers will have difficulty negotiating with suppliers as they do not know which cost elements can be reduced.

This paper proposes a framework for manufacturing cost estimation in the early design stage for the case of distributed manufacturing. The framework reduces risks of encountering unexpected cost at the commission of production that could result in a costly design change. The rest of paper is organized as follows. First, a literature review on manufacturing cost estimation is given. Then, our cost estimation framework is outlined. Finally, a case study showing cost estimation of a supplied component is illustrated followed by a conclusion and future work.

\section{$2 \quad$ Literature Review}

In this chapter, a summary of existing manufacturing cost estimation methods and cost elements is provided.

\subsection{Cost Estimation Methods}

Manufacturing cost estimation methods can generally be divided into two groups: qualitative methods and quantitative methods [3].

Qualitative methods are based on a comparative analysis between a new product and similar products manufactured previously. On the other hand, quantitative methods are based on a detailed cost analysis of product design, its features, and corresponding manufacturing processes instead of simply relying on the past data or tribal knowledge of an estimator. The qualitative methods do not provide a cost break down that can be used to understand cost elements that benefit from design change and cost negotiation.

There are several types of quantitative methods including Operation-based [4], Feature-based [5] and Break-down approaches [6]. Operation-based approach mainly estimates cost in terms of types of operations and considers material cost, factory expenses

1 In this paper, manufacturers refer to the organizations that design and/or produce products or components that need subassemblies from supplier organizations. The two roles are played by organizations in a distributed manufacturing chain. For example, prime contractor (a manufacturer) designs and produces cars which require instrument panel assembly from a subcontractor (a supplier). A subcontractor on the other hand can be a manufacturer ordering electrical harness from a supplier. 
and manufacturing processing cost as part of the costs associated with the time of performing operations. This approach focuses on accurate estimation of the manufacturing processing cost but provides less detailed consideration on other cost elements.

The feature-based cost estimation approach identifies cost-related features of the design and estimates their costs. However, existing approaches in this category only consider conventional machining process.

The break-down approach partitions manufacturing costs into cost elements. An estimation is applied to each cost element. The estimated manufacturing cost is a sum of all cost elements incurred during the production cycle. Cost elements include material cost, manufacturing process cost, maintenance cost, and repair cost. Other cost elements are insurance cost [6], overhead costs [7], and calculated manufacturing process cost based on the hourly usage of machinery [8].

For more accurate cost estimation, we adopt a cost break-down approach. However, our research focuses on estimating cost for distributed manufacturing. For that, we have to look into what data is available for the manufacturer, and use it to extend the scope of cost elements such as packaging and delivery cost. The scope of this paper and associated cost elements is described in 2.2.

\subsection{Cost Elements}

According to [9], selling price consists of machining, material, labor, indirect, selling and administrative expense and profit as shown in Fig. 1.

\begin{tabular}{|c|c|c|c|c|}
\hline & & & Profit & \\
\hline & & \begin{tabular}{|c} 
Selling and \\
Administrative \\
Expense
\end{tabular} & & \\
\hline & $\begin{array}{l}\text { Indirect } \\
\text { Expense }\end{array}$ & & $\begin{array}{c}\text { Total Cost to } \\
\text { Sell }\end{array}$ & Selling Price \\
\hline Machining & & Final Factory & & \\
\hline Labor & Prime Cost & & & \\
\hline Material & & & & \\
\hline
\end{tabular}

Fig. 1. Elements of Cost

Most research focuses on Final Factory Cost, however, it is necessary to widen the scope to Selling Price to include packaging and delivery cost in the Total Cost to Sell in order to estimate cost of a distributed manufacturer. To enable detailed cost analysis, cost elements for machining, tool, and defects should be added to Prime Cost. In conclusion, cost elements for distributed manufacturing are shown in Fig. 2.

\begin{tabular}{|c|c|c|c|c|c|c|c|c|}
\hline Material & Tool & Machining & Labor & Defect & Packaging & Delivery & $\begin{array}{c}\text { Selling \& } \\
\text { Administrative }\end{array}$ & Profit \\
\hline \\
Selling Price $=$ Distributed Manufacturing Cost \\
\hline
\end{tabular}

Fig. 2. Cost Elements for Distributed Manufacturing 


\section{Cost Estimation Framework}

In this chapter, we introduce a cost estimation framework for a supplied component. We assume that design of the component starts after target market, volume, and price are set as they are needed for the cost estimation.

Several efforts provided logic (cost elements and formula) for estimating costs. However, they can be difficult to apply in the early design stage of distributed manufacturing because data are not available. Therefore, it is necessary to incrementally increase the accuracy of cost estimation as shown in Fig. 3 - starting from using logic requiring the least information and add more details and data as they become available. The approaches used to update the logic and improve the accuracy include further breaking cost elements, decomposing parameters in formula, and collecting additional data and updating the database. Ways to collect data include investigating trends in the market, prototyping the component internally, contacting the supplier, contacting the equipment makers, and contacting raw material suppliers.

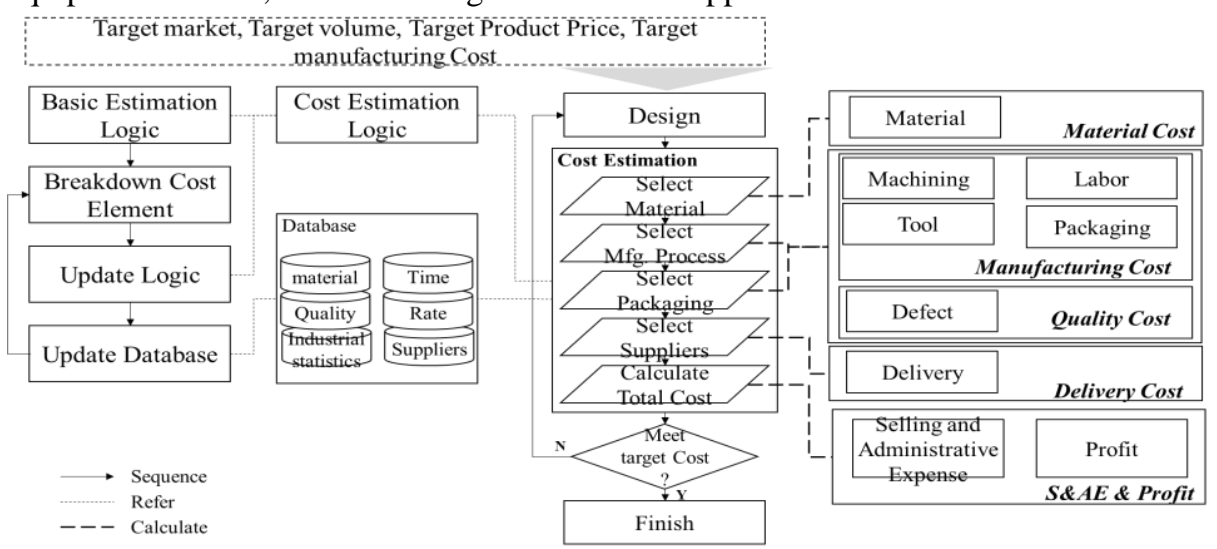

Fig. 3. Cost Estimation Framework for Distributed Manufacturing

As shown in Fig. 2, the Selling Price of the supplier (or supplied component) needs to be estimated. Therefore, the cost of the designed part is estimated by considering the material, the manufacturing process, the packaging method, and the anticipated supplier, and then comparing with the target cost. The right-hand side of Fig. 3 shows which cost elements (in Fig. 2) are related to cost estimation steps.

In the early stages of development, since every aspect of the design is not decided, such as the raw material or manufacturing method, assumptions have to be made on the parameters of cost elements. Therefore, only as the design of the product becomes more concrete, the cost can be estimated more accurately.

\section{Cost Estimation Method and Cost Breakdown}

In this chapter, we introduce a basic formula for each cost element and discuss their essential aspects. The formula can be adjusted for different supplied components and situations. Each of the cost elements is estimated per a part. 


\subsection{Material Cost}

Most of the research suggests estimating material cost using unit cost and amount. A basic estimation formula for material cost $C_{m a t}$ is given by

$$
\text { Material Cost } C_{\text {mat }}=m_{t} \times U_{\text {mat }},
$$

where $m_{t}$ is the total amount of the raw material and $U_{\text {mat }}$ is the unit cost for raw material However, the amount of material should be broken down into the net material, $m_{n}$, and loss material, $m_{l}$, to present an opportunity to reduce the lost material. The design engineer may improve the design or the manufacturer may work with supplier to improve the process to reduce the material loss. Materials are lost, for example, from preheating in the injection molding process and from chips or scraps in NC machining. Thus, material cost $C_{m a t}$, which characterizes material loss is, given by:

$$
\text { Material Cost } C_{\text {mat }}=\left(m_{n}+m_{l}\right) \times U_{m a t}
$$

\subsection{Machining, Labor and Tool Costs}

Generally, the basic estimation formula for machining is expressed as the product of machine rate and machining time [6].

$$
\text { Machining Cost } C_{m c n}=r_{m} \times t_{m}
$$

where $r_{m}$ is the machine rate and $t_{m}$ is the machining time. Machine rate is usually calculated by dividing the cost to operate a machine or machines for the needed processing duration by the duration itself. Details of machine rate estimation is beyond the scope of this paper, but it can be calculated approximately with depreciation, electricity and maintenance cost. Machining time can be subdivided into setup time $\left(t_{s}\right)$ operation time $\left(t_{o}\right)$ and nonoperation (idle time and down time) time $\left(t_{n o}\right)$ [10].

$$
\text { Machining Cost } C_{m c n}=r_{m} \times\left(t_{s}+t_{o+} t_{n o}\right) \text {. }
$$

Labor cost which is similar to machining cost is given by

$$
\text { Labor Cost } C_{l}=r_{l} \times t_{l} \text {, }
$$

where $r_{l}$ is the labor rate and $t_{l}$ is the labor operation time. A labor rate is the cost of labor that is used to derive the costs of various activities or products directly related to manufacturing. Calculating accurate labor costs can be difficult for distributed manufacturing because every supplier has different wages and compensation. Average labor rate of the industry can be used and is a good reference point for negotiation. The average labor operation time can be obtained by dividing the total number of products made during the day by the work time per day. However, it is also possible to apply the technique of analyzing the operation time such as Modular Arrangement of Predetermined Time Standards (MODAPTS) [11].

Tool cost, the cost of devices such as a mold or a jig, is calculated by dividing the price of the device by the target production quantity. 


$$
\text { Tool Cost } C_{\text {tool }}=\frac{\text { Tools } \text { Prices }}{\text { Target production volume }}
$$

\subsection{Defect Cost}

As every manufacturing process has failures, defect cost needs to be considered. Defect rate is difficult to predict before production starts and it can vary between suppliers. Therefore, the defect rate is typically set to the same as or lower than an average of historical defect rates. The formula to predict the defect cost, $C_{d f t}$, is given by

$$
\text { Defect Cost } C_{d f t}=\left(C_{m a t}+C_{m c n}+C_{l}\right) \times r_{d},
$$

where $r_{d}$ is the defect rate.

\subsection{Packaging Cost}

Packaging cost includes all the materials and processes needed for delivering the supplied component to the manufacturer.

$$
\text { Packaging Cost } C_{p k g}=p_{b} \div n_{p}+r_{l} \times t_{p},
$$

where $p_{b}$ is the cost for package box, $n_{p}$ is the number of parts for a box and $t_{p}$ is the packing time.

\subsection{Delivery Cost}

Delivery cost is the cost of delivering the packaged product from the supplier to the manufacturer. The method of estimating cost may vary depending on the transportation, but the formula below includes essential parameters for cost reduction analysis.

$$
\text { Delivery Cost } C_{d l v}=r_{d} \times d \div n_{t} \div n_{p} \text {, }
$$

where $r_{d}$ is the delivery rate, $d$ is the distance from supplier to buyer and $n_{t}$ is the number of boxes in a transport.

\subsection{Selling and Administrative Cost and Profit}

These cost elements can be estimated as percentage over other cost elements. Selling and administrative (S\&A) cost also includes research and development. These ratios vary by industries and suppliers and may be obtained from industry statistics such as in [12-13]. The S\&A ratio can be higher for a supplier with an R\&D center, such as a PCB manufacturer. In addition, the profit ratio can be negotiable, and it may increase for favorable partners such as those delivering consistent quality components and on-time delivery. The basic formulas for the two cost elements are:

$$
\begin{gathered}
\text { Selling and Administrative Cost } C_{s a c}=\left(C_{m a t}+C_{m c n}+C_{l}+C_{p k g}+C_{d l v}\right) \times r_{s a c} \\
\text { Profit } C_{p r f}=\left(C_{m a t}+C_{m c n}+C_{l}+C_{p k g}+C_{d l v}+C_{s a c}\right) \times r_{p r f}
\end{gathered}
$$


where $r_{s a c}$ is the selling and administrative ratio and $r_{p r f}$ is the profit ratio.

\section{Use case}

The use case is a scenario in which a refrigerator manufacturer needs injection-molding parts from a supplier. After the supplier receives the drawings, molds are manufactured. After the injection-molding part production and quality inspections are completed, they are put in protective tapes and delivered in boxes. Below, we discuss cost estimations and cost reductions experienced in this use case.

The component used $120 \mathrm{~g}$ of abs resin; therefore, according to (1):

$$
\text { Material Cost } C_{\text {mat }}=m_{t}(120 \mathrm{~g}) \times U_{\text {mat }}(\$ 2.7 / \mathrm{kg})=\$ 0.324 \text {. }
$$

However, it was determined that if two parts were produced at the same time in a single mold, machining, labor, and tool costs were reduced despite an increase in material cost. The increase in material cost came from additional resin needed for the sprue and runner $(6 \mathrm{~g})$ in the mold. Hence, material cost using (2) is:

Material Cost $C_{\text {mat }}=m_{t}(120 \mathrm{~g}+6 \mathrm{~g}) \times U_{\text {mat }}(\$ 2.7 / \mathrm{kg})=\$ 0.340$.

The price of the mold to produce the product is about $\$ 30,000$ and can be used 200,000 times. However, since we produce two parts in one mold,

$$
\text { Tool Cost } C_{\text {tool }}=\frac{\$ 300,000}{200,000} \div 2=\$ 0.75 \text {. }
$$

Machine rate for injection is calculated to be $\$ 24$ per hour and the machining time is 40 seconds for two pieces.

$$
\text { Machining Cost } C_{m c n}=r_{m}(\$ 24 / \text { hour }) \times t_{m c n}(40 s / 2)=\$ 0.13 \text {. }
$$

The operator extracts the injected parts from the machine and performs visual inspection. The labor rate is $\$ 30$ per hour and has the same tact time as machining time. Therefore, applying (3),

$$
\text { Labor Cost } C_{l}=r_{l}(\$ 30 / \text { hour }) \times t_{l}(40 s / 2)=\$ 0.17 \text {. }
$$

Since historically the average failure rate of the supplier in the use case was $2.0 \%$,

Defect Cost $C_{d f t}=\left(C_{m a t}(\$ 0.340)+C_{m c n}(\$ 0.33)+C_{l}(\$ 0.37)\right) \times r_{d}(2 \%)=\$ 0.01$.

After the manufacturing is completed, tape is attached, and a total of 100 parts are inserted into a $\$ 2$ container, which takes about 20 seconds per part. Therefore,

Packaging Cost $C_{p k g}=p_{b}(2) \div n_{p}(100)+r_{l}(\$ 30 /$ hour $) \times t_{p}(20 s)=\$ 0.187$.

A truck delivers parts with 400 boxes for $20 \mathrm{~km}$,

$$
\text { Delivery Cost } C_{d l v}=r_{d}(\$ 20 / \mathrm{km}) \times d(20) \div n_{t}(400 \times 100)=\$ 0.01 \text {. }
$$

Since the average $S \& A$ rate is $7.0 \%$ and profit rate is $8.0 \%$, they cost $\$ 0.11$ and $\$ 0.14$.

And finally, the total cost is a summation of all the cost elements: $\$ 1.85$ per part.

Discussion: If the estimated cost cannot meet the target cost, it is necessary to consider changing to cheaper raw materials, increasing the number of parts in the mold, or changing the packaging method to reduce the cost.

The estimated costs cannot be guaranteed to be available from the supplier but can be negotiated with supplier based on the estimation. For example, it may be possible to negotiate the defect rate, $\mathrm{S} \& \mathrm{~A}$ rate, etc.; or to come up with a supply chain strategy such as bulk buying raw materials at a lower price on behalf of multiple suppliers, arrange logistics services, etc. 


\section{Conclusion}

In this paper, we introduced a method to estimate costs for distribute manufacturing components. In order to estimate the cost of distribute manufacturing, selling price should be considered instead of final factory cost. We also introduced cost elements of the selling price for a more accurate cost estimation. Through this, a framework is proposed that incrementally enhance the detail of cost estimation during the design process. A use case illustrated the cost estimation process for a component and discussed how parameters identified in cost elements could be used for adjusting design and negotiating with suppliers.

Future work includes integrating the quantitative cost estimation approaches described in this paper with qualitative approaches. In this way machining time and working time can be better predicted based on data kept in a database of cost estimation. Therefore, defining data schema for such database is an important research topic.

\section{Disclaimer}

Any mention of commercial products is for information only; it does not imply recommendation or endorsement by NIST.

\section{References}

1. Ulrich, K.T., D.J. Ellison, Product Design and Development, McGraw-Hill, New York (1999).

2. Riitta K., Gautam A.: Something Old, Something New: A Longitudinal Study of Search Behavior and New Product Introduction. Academy of Management Journal 45(6), 11831194 (2002).

3. Adnan N., Jian D.: Product Cost Estimation: Technique Classification and Methodology Review. Journal of Manufacturing Science and Engineering 128(2), 563-575 (2005).

4. Shehab, E. M., Abdalla, H. S.: Manufacturing Cost Modeling for Concurrent Product Development. Robotics and Computer-Integrated Manufacturing 17(4), 341-353 (2001).

5. Zhang, Y. F., Fuh, J. Y. H., and Chan, W. T.: Feature-Based Cost Estimation for Packaging Products Using Neural Networks. Computer Industry 32, 95-113(1996).

6. Son, Y. K.: A Cost Estimation Model for Advanced Manufacturing Systems,” International journal of Production Research 29(3), 441-452(1991).

7. Bernet, N., Wakeman, M. D., Bourban, P. E., and Månson, J. A. E.: An Integrated Cost and Consolidation Model for Commingled Yarn Based Composites. Composites Part A: Applied Science and Manufacturing 4, 495-506(2002).

8. Ostwald, P. F., Engineering Cost Estimating, Prentice Hall, Englewood Cliffs, NJ (1992).

9. Colin D., Management and Cost Accounting, Cengage Learning EMEA (1985).

10. Jung, J.: Manufacturing Cost Estimation for Machined Parts Based on Manufacturing Features, Journal of Intelligent Manufacturing 13(4), 227-238(2002).

11. International MODAPTS Association, http://www.modapts.org/, last accessed 2019/4/13.

12. Macro trend, https://www.macrotrends.net, last accessed 2019/4/13.

13. Butler Consultant, http://research.financial-projections.com/, last accessed 2019/4/13 